\title{
Asturianos en Zacatecas (México) durante el siglo XVIII
}

\author{
Marcelino Cuesta Alonso
}

Universidad de Zacatecas

CES.XVIII, núm. 18 (2008), págs. 5-22. 
RESUMEN: A partir del siglo XVIII comienza a desarrollarse la corriente migratoria desde Asturias hacia América. En este trabajo pretendemos analizar la aportación que hizo Asturias al poblamiento de las tierras zacatecanas y cuáles fueron las actividades económicas a las que se dedicaron los emigrantes, así como algunas de sus costumbres sociales y los rasgos más destacados de sus vidas. Acotamos el período que va desde 1721 a 1808, el recogido en las tres fuentes utilizadas: Catálogo de Bienes de Difuntos en el Período Colonial, del Archivo Histórico del Estado de Zacatecas (AHEZ); Catálogo de Protocolos de Juan García Picón, del Archivo Histórico del Estado de Zacatecas (AHEZ); Inquisición, volumen 1129, expediente 3, f. 5, del Archivo General de la Nación (AGN) de México.

Palabras clave: Asturias. Zacatecas. Emigración. Minería. 
La publicación de la obra Los españoles en Aguascalientes durante la época colonial, en el año 2002 por parte del doctor Jesús Gómez Serrano, así como la obra de David Brading, Los españoles en México hacia 1792, y la existencia de diversos documentos sobre población de origen asturiano en Zacatecas me animó a llevar a cabo un breve estudio sobre este grupo de emigrantes que constituyen parte del estudio de los orígenes de la población zacatecana y de la reconstrucción de la historia de la Asturias ultramarina.

Una de las actividades económicas predominantes en Asturias desde tiempos de los romanos fue la explotación de la minería; con el tiempo el hierro y el carbón desplazarían al oro como actividades mineras predominantes y esa tradición sería continuada por los asturianos en las nuevas tierras descubiertas en el continente americano. Por ello, no es extraño que muchos de estos emigrantes se dedicaran precisamente a la minería en Zacatecas, región famosa por sus minas de plata durante la etapa colonial e incluso aún en nuestros días.

\section{Lugares de procedencia}

Con respecto a las localidades asturianas de procedencia de estos emigrantes tenemos en primer lugar la villa portuaria de Gijón que aportó cuatro emigrantes, seguida por Oviedo con tres. A continuación vendrían diversas localidades con un emigrante, éstas serían Avilés, Candás, Cangas de Onís, la Pedrera, Santa María de Villa del Mar, Santa Cruz de Jove, Rivera de Abajo, Sariego, Tiñana y Villaviciosa. Es decir había emigrantes de casi todas las tierras asturianas, del interior y de la costa, del occidente y del oriente.

\section{Los mineros}

Uno de estos mineros fue Diego Bernardo Álvarez y Valdés ${ }^{1}$, de quien conservamos noticias gracias a su testamento ${ }^{2}$ en donde solicita se proceda a inventariar

\footnotetext{
1 AHEZ, Catálogo de Bienes de Difuntos en el Período Colonial, del Archivo Histórico del Estado de Zacatecas (AHEZ), 279-1721-03-03, hojas 1-29.

2 El testamento aparece con la fecha de 29 de diciembre de 1718. AHEZ, Catálogo de Bienes de Difuntos en el Período Colonial, del Archivo Histórico del Estado de Zacatecas (AHEZ), 280-1721-03-03, hoja 176.
} 
la mina perteneciente a los bienes del difunto para proceder a su venta. De este asturiano sabemos que era caballero de la orden de Santiago, vecino y minero de Zacatecas, originario de Santa Cruz de Jove, en el concejo de la Villa de Gijón en el Principado de Asturias y obispado de Oviedo, España. Era, además, hijo de Domingo Álvarez Bernardo y Valdés y de Polonia Ramírez Jove del Rosal.

También se nos dice de él que era capitán, si bien no especifica la unidad a la que pertenecía, si bien pensamos que como otros muchos zacatecanos de la época, debía ser oficial de milicias. No debemos pensar que este personaje desempeñase dos oficios, el de minero y el de militar, sino más bien, que como era frecuente en la época los mineros acaudalados buscaban obtener algún título honorífico que diera más realce a su nombre y para ello conseguían los rangos militares. Hay que tener presente que no era fácil obtener títulos nobiliarios en América y los cargos en la Administración del Estado, así como los grados militares servían como sustitutos de la nobleza, entre los miembros de la raza española, quienes se esforzaron por mantener su estatus privilegiado sobre el resto de la población.

Precisamente el escritor mexicano Manuel Payno en su novela El hombre de la situación describe cómo el personaje principal en dicha obra obtiene el título de capitán después de haber hecho un importante donativo a la corona. Y, aunque se trate de una novela refleja un hecho que se repetía con frecuencia en la Zacatecas colonial como veremos en otros casos. Se puede decir por lo tanto que se trataba de una distinción honorífica, pues en la Zacatecas del siglo XVIII no eran frecuentes los conflictos con los nómadas chichimecas. De ahí que los milicianos apenas si eran llamados a defender el territorio.

Por otro lado, es necesario destacar el significado del término «minero» cuando se aplicaba tanto a un español peninsular como americano, no se pretende afirmar que trabajase dentro de una mina, sino más bien, que poseía una mina y se ocupaba de su explotación.

Como otros muchos asturianos, contrajo nupcias en Zacatecas, con Gertrudis de los Cobos Zambra, persona que aportó una dote a su matrimonio valorada en mil pesos que se sumaron al capital ya reunido por don Diego y que ascendía a dos mil pesos.

Don Diego también afirma ser noble y limpio, en referencia a que no poseía antepasados judíos. Y en cuanto a su nobleza, seguramente se trataba de un hidalgo, que, como muchos otros, al ser discriminado en el reparto testamentario por aplicarse las leyes del mayorazgo, optaban por la emigración hacia América o hacia la carrera militar. En el caso de este personaje, supo armonizar ambas posibilidades, lo que le valió para ir amasando un capital en dinero, esclavos, casas y posesiones mineras que después dejó en herencia a sus hijos doña Agus- 
tina de los Cobos Valdés, Diego de Valdés, franciscano, y Felipe Bernardo de Valdés y a doña María Rosa de los Cobos y Valdés.

En su testamento también disponía que sus restos fueran amortajados con el hábito de la orden de Santiago ${ }^{3}$, a la cual estaban vinculados algunos oficiales del ejército español y que aún hoy en día sigue vigente, pues no es extraño encontrarnos con oficiales españoles con dicho título todavía en el siglo XXI.

Finalmente, solicitaba en su testamento ser enterrado en la iglesia del convento de San Agustín en la ciudad de Zacatecas, lo que también implicaba la pertenencia a la alta sociedad, pues no todo el mundo estaba en condiciones de poder costear una tumba en el interior de las iglesias, siendo lo más común que la gente de menores recursos fuera enterrada en las inmediaciones exteriores de los edificios sacros.

Otro personaje de características similares fue el general Gonzalo Antonio Rosa Argüelles Guergo y Valdés, teniente de capitán general de Nueva Galicia, fronteras de San Luis Colotlán, Sierra de Tepec y subalternas, originario de Tiñana, Asturias, España, vecino y minero de Zacatecas, hijo de Lucas Rosa Argüelles Guergo y Valdés y de Isabel Menéndez Valdés Cornellana Argüelles, quien el 27 de septiembre de 1745 hizo testamento, el cual fue reclamado por la archicofradía del Santísimo Sacramento de la parroquia de Zacatecas, es decir, no pertenecía a ninguna orden pero sí a una cofradía, a la cual legó parte de sus bienes, que al no ser entregados por sus familiares, fueron reclamados por la archicofradía. La pertenencia a este tipo de instituciones religiosas tenía que ver con la consideración que recibían sus miembros como personas de bien, dado que las mismas se dedicaban a realizar obras de beneficencia pública como podía ser el aportar dotes a las jóvenes carentes de recursos.

Una de sus últimas disposiciones fue la de ser enterrado en la iglesia parroquia de Zacatecas, dejando el lugar a la libre decisión de sus albaceas testamentarios. En su testamento declaraba ser miembro de la orden terciaria de San Francisco, cofrade y hermano de la cofradía del Carmen, también de la de Nuestra Señora de los Dolores y al mismo tiempo de todas las cofradías y hermandades señaladas entre sus papeles. Él mismo explica el motivo de su pertenencia a tantas instituciones religiosas, para así poder recibir sus sufragios una vez muerto.

Curiosamente este personaje, a pesar de su cargo de general y de sus posesiones mineras, en su testamento se declara deudor de un sin fin de personas

3 En España, durante la Edad Media surgieron diversas órdenes militares cuya función era la de combatir a los musulmanes. La orden de Santiago nació en 1170 y perduró hasta 1873 fecha en la que fueron disueltas las órdenes religiosas por la Primera República española, quedando los títulos como meramente honoríficos. La orden permitía que algunos de sus miembros fueran casados. 
y de conventos a quienes solicita el perdón, justificándose por la escasez que había padecido en sus últimos días. Si bien deja dispuesto a sus albaceas que se ocupen de pagar sus deudas y compromisos a partir de sus bienes muebles ${ }^{4}$ Y prueba de que falleció dejando cuantiosas obligaciones la encontramos en los autos ejecutivos promovidos por la Archicofradía del Santísimo Sacramento de la parroquia de Zacatecas, contra los bienes del difunto Gonzalo Antonio ${ }^{5}$.

\section{Mercaderes}

Fue esta actividad frecuente entre muchos españoles instalados en América, sobre todo la de quienes llegaron en el siglo XVIII, cuando ya la obtención de nuevas tierras era más difícil por estar ya éstas repartidas. De hecho, todavía hoy es conocido el dicho de «gachupín abarrotero», en referencia al apodo con el cual los aztecas se referían a los españoles, por el tipo de calzado que solían portar, ya bien fuera por sus espuelas o por sus tacones y el término «abarrotero» en referencia a las tiendas de comestibles y demás utensilios de uso frecuente, denominados «abarrotes» en México.

Branding señala que el comercio era la actividad predominante entre los inmigrantes europeos y que incluso los que luego se dedicaron a la minería y a la explotación de haciendas, comenzaron como comerciantes, como medio con el cual hacer fortuna, que después reinvertían en otro tipo de actividades ${ }^{6}$.

Uno de estos comerciantes fue Alonso Sánchez de Valdés y Carrió originario del curato de La Pedrera, en el obispado de Asturias, en el reino de Castilla, España. Era descendiente de Bernardo Sánchez de Valdés y de Francisca de Carrió. Su oficio, según nos dice él mismo en su testamento, era el de «mercader en tienda de géneros de mercadería de Castilla y de la tierra». Por el inventario de sus mercancías se puede apreciar que vendía alimentos, bebidas, útiles domésticos, vestidos, telas, herramientas, armas e incluso instrumentos musicales como guitarras. Como otros muchos comerciantes de la época tenía numerosos deudores, quienes pasaron a serlo de sus herederos. Él mismo hace indicaciones para sus albaceas a fin de que pagasen a sus deudores, los cuales eran mayoritariamente abastecedores de su tienda. Era frecuente que las mercancías se entregasen de fiado y no se cobraban hasta que fueran vendidas por el

\footnotetext{
4 Catálogo de Bienes de Difuntos en el Período Colonial, del Archivo Histórico del Estado de Zacatexas (AHEZ), 1728-07-01, hoja 81.

5 Ibid., hojas 1-30.

6 David A. Brading, Mineros y comerciantes en el México borbónico (1763-1810), México, Fondo de Cultura Económica, 1971, pág. 149.
} 
abarrotero. A su vez, los compradores o clientes en las tiendas no pagaban sino cuando percibían sus salarios al final de la semana o de la quincena.

En su testamento ${ }^{7}$, deja por heredero a don Francisco Jove Bernardo, de quien no se dice su ascendencia, pero que por su apellido suponemos que era asturiano o descendiente de asturianos. El mismo heredero deja constancia del origen asturiano de su tío. Se manifestaba además católico en su testamento y disponía que su cuerpo fuese enterrado en la iglesia de la parroquia de Zacatecas.

También se dedicaba al comercio Nicolás de la Rosa originario de Oviedo. Éste solicita en su testamento ser enterrado en la capilla de la tercera orden de penitencia en el convento de San Francisco, lo que nos indica su condición de terciario franciscano, aunque engendró hijos naturales, es decir, fuera del matrimonio, pero que seguramente habrían sido engendrados antes de su ingreso en dicha orden, pues difícilmente habría sido admitido. Afirmaba también ser hijo legítimo de Antonio Rosa Argüelles y doña María González Colloto ${ }^{8}$. Su testamento presenta una relación de bienes en tan sólo dos hojas, siendo la mayor parte de ellos bienes domésticos, lo que nos hace suponer su fracaso en sus actividades comerciales, si tenemos en cuenta que en el caso de otros asturianos la relación de bienes solía extenderse a lo largo de varias hojas. Por lo tanto, a pesar de su prestigio social, no todos los españoles y en este caso asturianos triunfaban en el ejercicio del comercio.

Otro mercader fue José Francisco de Piz Jove, originario de Gijón, Asturias, España, hijo de Francisco de Piz Jove y de Lucrecia Angones Vigil ${ }^{2}$. El testamento del señor Piz es muy escueto. La razón seguramente debemos encontrarla en el hecho de que fue redactado vergonzosamente con la sola idea de nombrar heredero a su hijo natural, sin darnos muchos más detalles sobre la vida del testador, si bien la relación de sus bienes se extiende a los largo de trece hojas, señal de haber alcanzado una notable prosperidad económica.

Igualmente, de Felipe Varela Bermúdez, originario de Cangas de Onís, hijo legítimo de Francisco Varela y de Beatriz de Rodrigo Vidal, se dice que era mercader ${ }^{10}$. Observamos que se empleaba tanto este término de «mercader» como el de «ser del comercio» de la ciudad para hacer referencia al oficio de comerciante. Desgraciadamente no siempre se decía con qué tipo de mercancías negociaban, si bien suponemos, por similitudes con otros testamentos, que se

7 Catálogo de Bienes de Difuntos en el Período Colonial, del Archivo Histórico del Estado de Zacatecas (AHEZ),-1722-06-12, hojas 1-39.

$8 \quad$ Ibid.,1741-09-24, hoja 51; ibid. 1741-10-19, hoja 13.

$9 \quad$ Ibid.,1739-04-04, hojas 1-41.

10 Catálogo de protocolos de Juan García Picón, del Archivo Histórico del Estado de Zacatecas (AHEZ), 1751-02-12, hojas 28v.-30. 
trataba de comestibles, telas, prendas de vestir, herramientas, armas, especias y otros artículos de consumo frecuente.

Ese mismo término se empleó para designar el oficio de Alonso Viejo Baragaña, vecino y mercader de menudencias de esta ciudad, originario de la villa de Avilés, quien era hijo legítimo de Alonso Viejo Baragaña y de María Antonia López Jove $^{11}$. Se declaraba sin herederos directos descendientes y ascendientes por lo que entregaba sus bienes a sus amigos, si bien la relación de sus bienes era muy corta.

\section{Funcionarios}

En ocasiones los españoles que se trasladaban desde la Península a Zacatecas era para desempeñar un cargo público, normalmente muy bien remunerados y ambicionados por todos los españoles al constituir una fuente de ingresos garantizada y de por vida. Tal fue el caso de José Fernández Cachero, ensayador, fundidor y balanzario de la Real Caja de esa ciudad. Los ensayadores tenían por función comprobar la pureza de los metales preciosos, que se guardaban en las reales cajas ${ }^{12}$. Éste era originario de Candás, localidad marinera del concejo de Carreño en Asturias. Era hijo legítimo de Julián Cachero y de María de Bustos Prendes y difunto de María Gregoria Escolástica de Tagle Bracho de cuyo matrimonio tuvo por hijas legítimas a María Guadalupe y a doña Josefa Ángela Cachero Tagle Bracho a quienes declaró sus herederas.

Asimismo, encontramos dos escribanos. Uno, Manuel Antonio Suárez, escribano de Su Majestad, público y de Alhóndigas de Zacatecas, y de Paz y Guerra de las Fronteras de San Luis Colotlán y Sierra de Tepec, notario del Santo Oficio de la Inquisición, que era originario del pueblo de San Román en Sariego, Asturias $^{13}$. Éste declaró ser miembro de la orden Terciaria de San Francisco, cofrade de la Archicofradía del Santísimo Sacramento de la parroquia de Tlaltenango, también de la misma Archicofradía en la parroquia mayor de Zacatecas, de la de Santa Ana perteneciente a la misma iglesia y de cofrade de la sagrada congregación de la Anunciata en el colegio de la Compañía de Jesús en la misma ciudad y por último era cofrade de la del Santísimo Rosario del convento de Santo Domingo. La pertenencia a tantas cofradías denotaba su relevancia social y por supuesto su nivel de ingresos, ya que los cofrades ordinariamente debían hacer aportaciones a la institución para su sostenimiento.

\footnotetext{
$11 \quad$ Ibid., 24 de julio de 1734, hojas 4v.-6v.

$12 \quad$ Ibid., 1747-03-06, hojas 30v.-32.

$13 \quad$ Ibid., 12 de julio de 1745, hojas 34-61v.
} 
Su misma posición social viene corroborada por el hecho de disponer que su cuerpo fuera sepultado con dicho hábito en la iglesia parroquial mayor de la ciudad junto a la pila del agua bendita.

Afirmaba ser hijo legítimo de Bernardo Suárez y de María de Parajón. Y a su vez estaba casado con Luisa Isabel Álvarez Vallín de quien no tuvo hijos, si bien, adoptó sus hijos naturales, Vicente y Nicolás Suárez, nacidos de su relación con José de Gorcochea, natural de Vizcaya bajo promesa de matrimonio, luego no cumplido. Este aspecto era importante recalcarlo pues así se destacaba la inocencia de la esposa engañada y el mismo marido legítimo se libraba de posibles críticas por haberse casado con una madre soltera.

Otro fue Juan García Picón, escribano de Su Majestad, Real Hacienda, Caja y Minas y Registros de Zacatecas, y de Paz y Guerra de Nueva Galicia, originario de Oviedo, Asturias ${ }^{14}$. Era hijo legítimo de Andrés García Picón y de Ana Martínez de Evia. Declaró haberse casado con Ana María Díaz Vigil en los reinos de Castilla de cuyo matrimonio nacieron cuatro hijos de los cuales tres fallecieron «en tierna edad», quedando vivo Luis García Picón para fallecer después en Manila, Filipinas, dejando dos hijos de su unión con Águeda Sánchez Durán a quienes reconoce como nietos y por lo tanto como herederos suyos. Disponía en su testamento que su hija política fuera informada de su muerte y se le hicieran llegar los bienes pertenecientes a sus hijos para su administración mientras alcanzasen la mayoría de edad.

Afirmó después haberse casado en segundas nupcias con María Dolores la Reza y Acelain de cuyo matrimonio no tuvieron hijos, si bien criaron dos niñas a las que considera sus hijas y herederas. Asimismo, hace heredero al padre fray Manuel de la Reza y Acelain, franciscano y hermano de su esposa.

Al igual que otros personajes destacados de su sociedad, perteneció a más de una hermandad, concretamente era cofrade del Santísimo Sacramento, de la de Santa Ana, de la cofradía de la Soledad, así como hermano en la de San Agustín.

Otro asturiano que desempeñó funciones administrativas en Zacatecas fue José de Peón Valdés. Nacido en Villaviciosa (Asturias) en 1750. Era hijo de don José de Peón Valdés y de doña María Alonso de Costales ${ }^{15}$. Según la Enciclopedia Hispanoamericana de heráldica, genealogía y onomástica de los hermanos Alberto y Arturo García Carraffa se dice en la voz «Peón» que la familia Peón era

\footnotetext{
14 Catálogo de Bienes de Difuntos en el Período Colonial, del Archivo Histórico del Estado de Zacatecas (AHEZ), 1755-12-31, hoja 57.

15 Archivo General de la Nación (AGN), ramo: Inquisición, volumen 1129, expediente 3, f. 5: «El señor del Santo Oficio contra Don Josef Monter, tesorero de las reales cajas de dicha ciudad por proposiciones», Zacatecas, 1790.
} 
originaria de la casa solariega Peón de la Torre y que esta familia fue una de las más nobles de Asturias, destacándose numerosos miembros de la familia por el desempeño de oficios honoríficos como regidores, jueces, procuradores generales y oficiales del ejército. Durante doce años estuvo vinculado a la universidad de Oviedo, como estudiante y profesor. En ella obtuvo el grado de bachiller en Artes y Leyes. Desempeñando más tarde el puesto de maestro sustituto de la cátedra de instituciones civiles. También sabemos que impartió clases de Derecho civil y canónico, asignaturas sobre las que también escribió algunos ensayos. Además tuvo por esos años la oportunidad de ejercer su profesión como abogado relator y secretario de la universidad durante cuatro años.

El 26 de enero de 1785 fue admitido por la audiencia de Oviedo como abogado de los reales consejos, lo que suponía conceder licencia para poder litigar en los tribunales reales. Peón Valdés ejerció entonces como abogado en Villaviciosa. Participó a su vez en algunas comisiones para el Consejo de Castilla en las proximidades a Madrid; y en 1786 concursó en unas oposiciones para la plaza de relator del Consejo de Indias.

Posteriormente se traslada a la Nueva España y en Zacatecas comenzó su carrera en Las Indias, ejerciendo el puesto de teniente letrado del que apenas había sido nombrado intendente de Zacatecas, Felipe Cleere.

El nombramiento lo recibió el 21 de mayo de 1792, a la edad de treinta y tres años. Siete días más tarde, al no poder ejercer Cleere como intendente, Peón Valdés fue designado para ejercer el cargo como interino hasta que Cleere pudiese integrarse al mismo. Sin embargo esta situación se prolongó hasta noviembre de 1794. El día 21 de dicho mes, Cleere le manifestó a Peón que el clima de Zacatecas le había mermado su salud por lo que le era imposible encargarse de la intendencia. Le pedía que continuara atendiendo el cargo como lo había hecho durante las ausencias anteriores, mientras se restablecía de su enfermedad. La presencia de Cleere en Zacatecas fue muy breve, pues falleció a los pocos días, teniendo Peón Valdés que continuar ejerciendo como intendente. Peón informó del suceso al virrey Miguel de la Grúa Talamanca y Branciforte, marqués de Branciforte (1794-1798) el día veintiocho del mismo mes. El 6 de diciembre de 1794, el virrey le nombró como encargado de la intendencia, hasta la llegada de Francisco Rendón, en julio de 1796. Durante ese tiempo pudo adquirir mucha experiencia sobre el gobierno y la impartición de justicia en Zacatecas, lo que le serviría para posteriormente convertirse en el asesor de los futuros intendentes. A su vez las continuas y prolongadas ausencias de los intendentes, quienes delegaban en Peón Valdés el gobierno de la misma, le sirvieron para ir comprendiendo cada vez mejor los problemas y la complejidad jurídica que presentaban los conflictos zacatecanos. Por otro lado, su presencia en Zacatecas coincidió 
con los años de la invasión napoleónica de España y la posterior guerra de independencia. Desde Zacatecas, Peón Valdés buscó recaudar dinero para la causa independentista española y al mismo tiempo se preocupó por evitar cualquier movimiento propagandístico a favor de José Bonaparte entre los zacatecanos. A partir de 1810, cuando en México comenzó el proceso de independencia, combatió desde su puesto de letrado la difusión de escritos a favor de los insurgentes y procedió al arresto de algunos de los líderes independentistas en Zacatecas como los hermanos Rosales, a quienes más tarde dejaría en libertad. El mismo Peón Valdés fue apresado y encerrado por los partidarios de Hidalgo, si bien finalmente sería puesto en libertad.

Tras consumarse la independencia, al necesitar el nuevo país expertos en el campo jurídico, Peón Valdés pudo continuar ejerciendo como juez en Zacatecas y no sólo eso sino que también llegó a ser el primer presidente del Tribunal Supremo de Zacatecas, en 1824.

\section{Presbiteros}

Sólo encontramos para la época un sacerdote de origen asturiano en la ciudad. Se trata de don Andrés José Vázquez Castales, originario de la villa de Gijón, en el Principado de las Asturias, presbítero domiciliario del obispado de Guadalajara y vecino de Zacatecas ${ }^{16}$. El mero hecho de ser escasos los sacerdotes y religiosos que vivían en Asturias nos ayuda a comprender su reducido número en el continente americano.

Como otros muchos sacerdotes, al trasladarse al Nuevo Mundo dejaba atrás a sus padres y hermanos, lo cual no implicaba una total desvinculación, pues las obligaciones jurídicas y los lazos familiares continuaban existiendo. De hecho, este personaje se preocupa por dejar sus últimas voluntades en Zacatecas con la intención de que los bienes heredados de sus padres, y más concretamente una casa, pasase a manos de una sobrina y en caso de fallecimiento de ésta a sus hijos legítimos.

\section{Estados civiles}

Nos pareció también interesante indagar un poco sobre las costumbres de los asturianos en materia civil y lo cierto es que nos hemos encontrado con un elenco

16 Catálogo de protocolos de Juan García Picón, (AHEZ), 1754-01-12, hojas 3v.-4v. 
muy variado de situaciones. Felipe Varela Bermúdez se dice que era célibe ${ }^{17}$, si bien en otros casos se le denomina soltero ${ }^{18}$. Y con este término, probablemente, buscaba resaltar no sólo la soltería, sino también impedía que alguien pudiera reclamar a sus herederos una parte de su patrimonio.

En la misma situación suponemos que se debía encontrar Mateo Fernández de Estrada, pues en su testamento dejaba todos sus bienes a un sobrino, lo cual no sería así si hubiera tenido hijos propios o adoptivos ${ }^{19}$. Y lo mismo hizo Felipe Varela Bermúdez quien dejó en su testamento a dos sobrinos como herederos de sus propiedades ${ }^{20}$.

También Antonio de la Rosa Argüelles era soltero y además en su testamento subraya dicho estado destacando que no había contraído matrimonio, ni esponsales de presentes ni de futuro, ni tampoco estar ligado a él ni de palabras ni en otra forma alguna ${ }^{21}$. Suponemos que con dicha declaración impedía cualquier reclamación testamentaria por parte de las dos mujeres con quienes declara haber tenido un hijo y una hija, ambos naturales, Pedro Miguel y Manuela Paulina Antonia, de unos quince y dieciséis años. En el caso de su hija afirma que desde los dos años la había mantenido y entregado para su crianza a doña María Dolores Larreta, a quien declara su comadre. A sus dos hijos los nombra herederos de todos sus bienes. No así a sus madres quienes ni siquiera son nombradas por el testador.

Sin embargo ése no era el estado civil más común. Muchos de los asturianos de Zacatecas eran casados con mujeres de la ciudad. En esa situación se encontraban por ejemplo Francisco López, casado con María Ana Muñiz Parada con quien tuvo tres hijas ${ }^{22}$.

Lo mismo podemos decir de José Fernández Cachero de Candás, casado con María Gregoria Escolástica de Tagle Bracho con quien tuvo dos hijas ${ }^{23}$.

Algunos recurrían a terceros para contraer matrimonio por poderes con mujeres de otras localidades novohispanas y así Pedro Álvarez Cantón, residente en Zacatecas, vecino y minero del real de San Antonio de Tepeque, jurisdicción de la villa de Jerez, originario de la ciudad de Oviedo, designó a Juan de Urbiaco vecino de Guadalajara, para que desposara contrayendo matrimonio en su nombre a María Antonia de Ubiarco, posiblemente hermana de Juan² ${ }^{24}$

\footnotetext{
17 Ibid., 1751-02-12, hojas 28v.-30.

$18 \quad$ Ibid., 1744-01-03, hoja 3.

$19 \quad$ Ibid., 1721-04-20, hojas 99-102.

$20 \quad$ Ibid., 1751-02-12, hojas 28v.-30.

${ }_{21}$ Ibid., 1741-10-19, hoja 13.

$22 \quad$ Ibid., 13 de agosto de 1734, hojas 8v.-10v.

$23 \quad$ Ibid., 6 de marzo de 1747, hojas 30v.-32.

${ }^{24}$ Ibid., 1 de agosto de 1739, Zacatecas, hojas 6-7v.
} 
De igual manera se daban situaciones de casados en Asturias que llegaban a Zacatecas para hacer fortuna como Francisco de Pando, oriundo de Villaviciosa y casado con María Francisca de Pando con quien tuvo una hija y al momento de partir su esposa esperaba un segundo hijo. Ambos descendientes son nombrados herederos por su padre, quien fallece en Zacatecas ${ }^{25}$.

Algo parecido le sucedió a un militar, ya mencionado, el general Gonzalo Antonio Rosa Argüelles Guergo y Valdés, quien declaraba además estar casado en primeras nupcias con doña Francisca Álvarez de Ron, originaria del Principado de Asturias, pero de cuyo matrimonio no tuvo hijos. Posteriormente contrajo segundas nupcias en Nueva España con Ana Fernández de Córdoba, de quien procrearía a su hija legítima María Manuela Irene del Carmen Rosa Argüelles Fernández de Córdoba. Si bien en su testamento declara que antes de haber contraído matrimonio en Nueva España tuvo una hija natural llamada doña Vicenta Rosa Argüelles ${ }^{26}$.

Hemos registrado otro caso en el que se reconocía a los hijos naturales como herederos, por lo tanto las relaciones fuera del matrimonio, también se dieron entre la colonia asturiana de Zacatecas. Nicolás Rosa Argüelles en su testamento nombraba herederos a sus hijos naturales Pedro Miguel y Manuela Paulina Antonia Rosa ${ }^{27}$.

Algo parecido le sucedió a José Francisco de Piz Jove, quien se declaraba suelto y libre de matrimonio tanto en los reinos de Castilla como en América, si bien reconoce ser padre de un hijo natural llamado Pedro, de unos catorce o quince años y concebido con una mujer también soltera, en este caso la madre era también asturiana, pues su hijo, en un escrito posterior, se dice natural de la villa de Gijón ${ }^{28}$.

\section{El retorno a Asturias}

En Asturias se denomina «indianos» a todos los emigrantes que se trasladaron a Las Américas y allí lograron hacer fortuna para después regresar de nuevo a la tierra de sus orígenes y desarrollar la vida típica de persona acaudalada. De hecho, todavía hoy en día es posible contemplar en Asturias muchas casas solariegas con una palmera en su jardín delantero, planta no autóctona en aque-

\footnotetext{
25 Ibid., 27 de septiembre de 1735, hojas 92v.-94v.

26 Ibid., 1728-07-01, hoja 81.

$27 \quad$ Ibid., 24 de septiembre de 1741, hojas 9v.-13.

28 Catálogo de Bienes de Difuntos en el período Colonial, del Archivo Histórico del Estado de Zacatecas (AHEZ), 1739-04-04, hojas 1 y 60.
} 
llas latitudes, pero que ha logrado aclimatarse en las zonas menos frías y que constituyó durante largos años el símbolo distintivo de los indianos.

El carácter típico del asturiano suele llevarle a ser muy nostálgico de su tierra, de ahí que éstos se caractericen por retornar siempre que pueden a sus lugares de origen, sin embargo, en el caso de los que emigraron a Zacatecas, el porcentaje de los que regresaron es más bien pequeño, pues únicamente encontramos dos casos en los que se produjo esa vuelta a la patria.

De todos modos, los asturianos que se desplazaban a Zacatecas no solamente se movían con el afán de lograr fortuna. Había quienes lo hacían con la idea de comenzar una nueva vida en América, puesto que, como hemos dicho, su tierra originaria no les ofrecía muchas oportunidades. Al contraer matrimonio, o bien al engendrar a sus hijos en Zacatecas quedaban vinculados definitivamente a la ciudad y por eso la mayor parte de ellos decidían consumir sus vidas y fallecer en el territorio novohispano.

Seguramente los pocos que regresaban, lo hacían por haber dejado mujer e hijos en Asturias o bien por no haber podido contraer nupcias o cualquier otro tipo de relación en dichas tierras.

Un caso en el que se produce el retorno a las tierras originarias, en la villa de Gijón ${ }^{29}$, fue el de Diego García de Argüelles, a quien la muerte le encontrará en su tierra natal, si bien sus disposiciones testamentarias se habían quedado en Zacatecas.

En otro testamento, en el del general Gonzalo Antonio Rosa Argüelles, se habla de Don Diego García Rosa Argüelles, posiblemente familiar suyo, de quien se dice que se «había transportado para los reinos de Castilla» ${ }^{30}$, lo que nos hace suponer que fue otro caso de asturiano vuelto a la tierra originaria.

\section{Conclusión}

Como ya ha señalado Branding, la población asturiana, junto con la de todo el norte de España, sufrió a lo largo del siglo XVIII un importante incremento demográfico que llevó a una parte de la población a emigrar al Nuevo Mundo ${ }^{31}$. Si bien este autor ha destacado la importancia de los montañeses, que hoy en día se entiende por tales a los santanderinos, parece que con el término engloba

29 AHEZ, Catálogo de protocolos de Juan García Picón, 20 de abril de 1751, hojas 99-102.

30 Catálogo de Bienes de Difuntos en el Período Colonial, del Archivo Histórico del Estado de Zacatecas (AHEZ), 1728-07-01, hoja 55.

31 David A. Brading, Mineros y comerciantes en el México borbónico (1763-1810), México, Fondo de Cultura Económica, 1971, págs. 149-150. 
también a los asturianos. De hecho, estos segundos fueron mucho más numerosos que los santanderinos en la ciudad de Zacatecas pues en el período estudiado sólo hay constancia de la presencia de un habitante de Santander en la ciudad.

Los asturianos de Zacatecas, como miembros de la casta social blanca europea, gozaron de los privilegios propios de este grupo, en el sentido de que pudieron desempeñar trabajos como militares, funcionarios públicos, mineros y comerciantes; e incluso encontramos un párroco, puestos que traían consigo una remuneración económica muy superior a la que podían alcanzar los miembros de otras clases sociales. A ello habría que añadir, como afirma Agustín Cue Cánovas, que gozaban siempre de la protección de los españoles ya establecidos en el territorio, lo cual constituía un aliciente para los recién llegados ${ }^{32}$. Este mismo autor, citando a Humboldt, afirma que la población europea hacia finales del siglo XVIII, tan sólo constituían en México 1,5\% de la población del virreinato ${ }^{33}$. Y el mismo Humboldt sostiene que hasta el más miserable de los europeos que no hubiese recibido formación se creía superior a los blancos nacidos en el Nuevo Mundo ${ }^{34}$.

El censo de Revilla Gigedo para el año 1792 afirma que en Zacatecas vivían 292 europeos, suponemos que mayoritariamente españoles, a los que diferencia de los españoles, supuestamente americanos, mucho más numerosos, unos 5.644 en la ciudad de Zacatecas para las mismas fechas ${ }^{35}$. Desgraciadamente en dicho censo no se especifica el origen de los españoles europeos. Nosotros hemos podido constatar la presencia de 18 asturianos en la ciudad. Número que resultaba muy reducido frente a una población que según Humboldt alcanzaba en 1793 los 25.495 habitantes $^{36}$. Sin embargo la proporción era mayor que en ciudades como Guanajuato en donde sólo había 11 asturianos en 1792 frente a una población total de $32.098^{37}$.

Es cierto que para la época tratada, el siglo XVIII, el sistema de castas estaba debilitándose ${ }^{38}$, pero todavía se percibe su influencia, precisamente como consecuencia del mantenimiento de dichos privilegios en materia laboral.

\footnotetext{
32 Agustín Cue Cánovas, Historia social y económica de México 1521-1854, México, Trillas, 1997, pág. 123.

33 Op. cit., pág. 134.

34. Alejandro de Humboldt, Ensayo político sobre el reino de la Nueva España, México, Porrúa, 1978, pág. 76.

35 Cfr. AHEZ, Censo de Revilla Gigedo, Fondo: Intendencia, Serie: Gobierno, en el Archivo Histórico del Estado de Zacatecas, 25 de julio de 1792.

36 Alejandro de Humboldt, Ensayo político sobre el reino de la Nueva España, Porrúa, México 1978, pág. 38.

37 David A. Brading, Mineros y comerciantes en el México borbónico (1763-1810), Fondo de Cultura Económica, México 1971, pág. 336.

38 Agustín Cue Cánovas, Historia Social y Económica de México 1521-1854, Trillas, México 1997, pág. 132.
} 
Otro elemento a destacar es que la mayoría de estos asturianos dejaba descendencia en la ciudad, sin embargo no era una prole muy numerosa, posiblemente porque el primer objetivo de este grupo era el de hacer un patrimonio partiendo de cero. Cuando lograban dicho patrimonio, entonces se planteaban formar familia o por lo menos tener descendencia, procediendo luego a reconocer a sus hijos naturales como herederos.

Jesús Gómez Serrano, citando a Brading, ha destacado la importancia que tenía el matrimonio para los españoles que se afincaban en Aguascalientes ${ }^{39}$, estado próximo a Zacatecas. Sin embargo, por lo que hemos podido observar en Zacatecas, los asturianos, si bien también se casaron con mujeres del lugar, no siempre seguían esa conducta y eran comunes las relaciones extramatrimoniales, con lo cual no siempre recurrían a la unión marital para lograr una posición social, que en muchos casos les era dada por el mero hecho de ser españoles como consecuencia de lo que en México se denomina «el malinchismo».

Por último, queremos destacar otro aspecto que llamó nuestra atención, ya que nos encontramos con el nombre de dos minas, una denominada La Asturiana, ubicada en las cercanías de Zacatecas, y otra llamada Santa Bárbara, alias el Principado, en alusión al título que posee la región asturiana desde el año $1388^{40}$. Ello significa que posiblemente ambas fueron explotadas por mineros asturianos en sus orígenes. De hecho aún hoy en la ciudad de Zacatecas se puede encontrar una calle dedicada a la mina La asturiana.

\section{Listado de asturianos residentes en Zacatecas desde 1724 a 1808}

1. Diego Bernardo Álvarez y Valdés, caballero de la orden de Santiago, vecino y minero de Zacatecas, originario de Santa Cruz de Jove, Asturias, España.

2. Alonso Sánchez de Valdés y Carrió, originario de La Pedrera, Asturias, España, hijo de Bernardo Sánchez de Valdés y de Francisca de Carrió.

3. Juan Cosme de la Campa, originario de Santa María de Villa Mar, Asturias, España, hijo de Juan Cosme de la Campa y de María de Villa Mar.

\footnotetext{
39 Jesús Gómez Serrano, Los españoles en Aguascalientes durante la época colonial, Zapopan, El colegio de Jalisco, 2002, pág. 79.

40 Los conflictos entre Juan I de Castilla y el duque de Lancaster, quienes se disputaban el reino de Castilla, motivó el matrimonio entre sus hijos para de este modo poner fin a la lucha. Enrique de Castilla y Catalina de Lancaster, contrajeron matrimonio y como parte de los regalos nupciales recibieron el título de príncipes de Asturias de modo semejante a como en Inglaterra el príncipe heredero recibe el título de príncipe de Gales. Desde entonces el título de príncipe de Asturias estará siempre ligado al heredero de la Corona de Castilla y de España. Enrique III (1379-1406), hijo de Juan I, fue el primer príncipe en poseer este título.
} 
4. General Gonzalo Antonio Rosa Argüelles Guergo y Valdés, teniente de capitán general de Nueva Galicia, fronteras de San Luis Colotlán, Sierra de Tepec y subalternas, originario de Tiñana, Asturias, España, vecino y minero de Zacatecas, hijo de Lucas Rosa Argüelles Guergo y Valdés y de Isabel Menéndez Valdés Cornallana Argüelles.

5. José Francisco de Piz Jove, originario de Gijón, Asturias, España, hijo de Francisco de Piz Jove y de Lucrecia Angones Vigil.

6. Nicolás de la Rosa Argüelles, vecino y del comercio de Zacatecas, originario de Oviedo, Asturias.

7. Felipe Varela Bermúdez, vecino y mercader de Zacatecas, soltero, originario de Cangas de Onís, Asturias, España, hijo de Francisco Varela y de Beatriz Rodrigo Vidal.

8. Manuel Antonio Suárez, escribano de Su Majestad, público y de Alhóndigas de Zacatecas, y de Paz y Guerra de las Fronteras de San Luis Colotlán y Sierra de Tepec, notario del Santo Oficio de la Inquisición, originario de Sariego, Asturias, España.

9. Francisco Jove Bernardo, originario de Gijón, Asturias, España, vecino y minero de Zacatecas, hijo de Baltasar Jove Bernardo y de María Méndez de Valdez.

10. Juan García Picón, escribano de Su Majestad, Real Hacienda, Caja y Minas y Registros de Zacatecas, y de Paz y Guerra de Nueva Galicia, originario de Oviedo, Asturias, España, hijo de Andrés García Picón y de Ana Martínez de Evia.

11. Pedro Álvarez Cantón, residente en Zacatecas, vecino y minero del real de Tepec, jurisdicción de la villa de Jerez, originario de la ciudad de Oviedo.

12. Franciso López, vecino de esta ciudad, originario del puerto de la Ribera de Abajo, obispado de Oviedo, Principado de Asturias.

13. Alonso Viejo Varagaña, vecino y mercader de menudencias de esta ciudad, originario de la villa de Avilés.

14. Don José Fernández Cachero, ensayador, fundidor y balazario de la Real Caja de esa ciudad, originario de la villa de Candás, en el concejo de Carreño, obispado de Oviedo.

15. Francisco de Pando, español, originario de Villaviciosa, obispado de Oviedo, en el Principado de Asturias, en los reinos de Castilla, hijo legítimo de Marcos de Pando y de Ana María Álvarez de Condarco, difuntos; casado con María Francisca de Pando, vecina de dicha villa, con quien tuvo como su hija legítima a María Francisca, y declara que al momento de haber salido de dicha villa y Principado de Asturias, quedó su mujer preñada. 
16. Don Diego García de Argüelles, vecino que fue de Zacatecas, muerto en la villa de Gijón, en el Principado de Asturias.

17. Don Andrés José Vázquez Castales, originario de la villa de Gijón, en el Principado de las Asturias, presbítero. 